RESEARCH ARTICLE

\title{
Elucidating Knowledge level of Vegetable growers on Retail Marketing in Telangana
}

\author{
Anusha V V S S ${ }^{* 1}$, Padma S R ${ }^{2}$, Balasubramaniam $\mathbf{P}^{1}$, Patil SG ${ }^{3}$ \\ ${ }^{1}$ Department of Agricultural Extension and Rural Sociology, Tamil Nadu Agricultural University -641 003 \\ ${ }^{2}$ Agricultural College and Research Institute, Tamil Nadu Agricultural University, Coimbatore -641 003 \\ ${ }^{3}$ Department of Physical Sciences and Information Technology, Tamil Nadu Agricultural University, Coimbatore -641 003
}

\begin{abstract}
In the scenario of extending the organized retail markets to tier II and III cities of India, a preliminary inquiry in Ranga Reddy district highlighted the non-participation of the vegetable growers in the retail marketing system. To understand further, the knowledge level that contributes to the behavior is examined in this study. A total of 150 vegetable growers of the peri-urban area were selected by simple random sampling and were approached with a structured interview schedule. A teacher-made test was posed to elucidate the knowledge in 4 aspects - awareness, marketing process, pricing, and additional services provided. It was found that 64.00 per cent of the respondents had a medium knowledge of retail markets. The correlation analysis disclosed a significant positive relationship of knowledge level with education, the area under vegetables, market orientation, market intelligence, information-seeking behavior at 1 per cent, and economic motivation, landholding at 5 per cent. It was observed that age and experience in vegetable farming are negatively significant with 0.05 per cent of probability. Execution of -step-wise regression to fit the model where education, market orientation, the area under vegetable production, annual income, economic motivation, decision-making ability with unstandardized coefficients $0.994,0.953,0.482,-4.285 \mathrm{E}-6,0.197,0.222$ respectively were found significant with 39.7 per cent of coefficient of determination (R2). Converting knowledge into actions requires interactions with retail market agencies that build trust.
\end{abstract}

Keywords: Knowledge; Peri-urban; Retail market; Vegetable farmers.

\section{INTRODUCTION}

The scheme 'Doubling farmers income by 2022', introduced by the Government of India, however, claimed unrealistically, arose from the fact that the average income level of farmers is deficient, i.e., Rs. 6,491/month (Thiagu, 2013), which needs to be improved. This reaffirmed the shift of extension approach from production to market-oriented, where extension service starts from rendering market information for selecting crops and extends up to providing forward (processing industries) and backward (input dealers) linkages (Heijden, 2013).

The research analysis of Schreinemachers et al. (2018) concluded that vegetables stand as a hope that extends food and nutrition security, with the economic potential act as a critical element in diversification. However, the intricate problems associated with vegetable production - increase in input cost, lack of market information, price fluctuations, inadequate transport facilities, distant markets, exploitation of intermediaries are stated in various research studies (Srinivas et al. , 2016; Kiran, 2018; Kshash, 2018).

The marketing of vegetables is highly reliant on the unorganized retailing sector (as street vendors), which leads to the market channel of farmer wholesaler - retailer - consumer associated with many intermediaries (Commission agents). This inefficient system leads to price spread (variation in the price paid by the consumer and price received by the farmer), leaving the farmer in losses and intermediaries at a benefit.

On the contrary, organized retail marketing is handled by the taxpaying entities connecting the farmers with consumers with an efficient supply chain mechanism. A report of FAO, 2010 asserted that there is an increased income for farmers in association with organized retails by attaining 
higher prices. This increase is due to reduced transportation costs, commission charges, and packaging material costs. Collection centers of retail outlets bring markets closer to farmers, cutting down the price spread.

The supermarkets and hypermarkets culture profound in metropolitan cities reach out to the peri-urban farmers for a regular supply of quality vegetables. The study area, Ranga Reddy, is one such peri-urban area, stands top (RSSS data, 2019-20) in the extent of vegetable land coverage and production. A preliminary survey highlights the dearth of farmer's participation in retail marketing. The reason speculated for such behavior is the lack of knowledge about the process of retail marketing, benefits, and additional services associated with it. As depicted in Figure 1, the study's conceptual model states the contribution of profile variables to form knowledge, a predecessor for forming an opinion (Paul, 2017). To have conclusive results, this study was taken up to understand the knowledge level of the farmers towards retail marketing and the factors of profile that contribute to it.

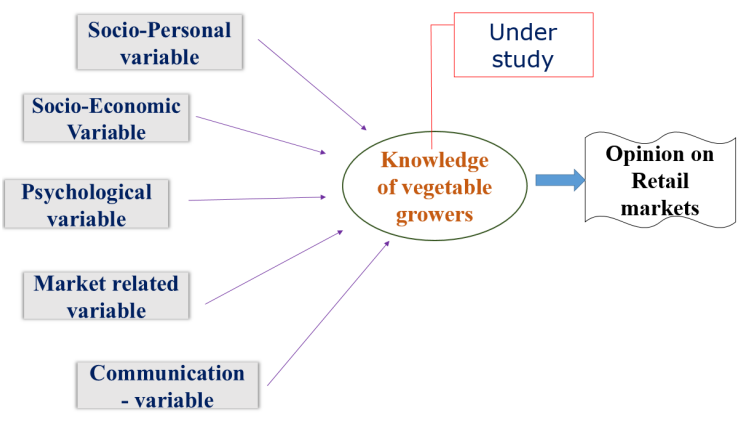

Figure 1-Conceptual model of the study depicting the contribution of profile variables towards knowledge of retail marketing, which in turn accord to opinion towards retail markets.

\section{MATERIAL AND METHODS}

Ranga Reddy district of Telangana lies between North latitude of $16^{\circ} 30^{\prime}-18^{\circ} 20^{\prime}$ and $77^{\circ} 30^{\prime}$ $79^{\circ} 30$ East longitude was conveniently selected for the study. From which purposive selection of Chevella, Ibrahimpatnam, Moinabad Mandals based on the average area vegetable cultivation for three years (2018-2021, RSSS data). Identification of three villages purposively from each Mandal, where the area under vegetable production for 2020 21 was maximum. A proportionate selection of vegetable growers led to a total sample of 150, who were contacted with a structured interview schedule. A teacher-made test was constructed to elucidate knowledge on retail marketing of vegetable farmers. The questions were both open-ended and multiplechoice questions under four aspects "Knowledge of Retail markets (awareness)," "Retail marketing process," "Charges/prices of retail marketing," "Additional services provided by the Retail markets" with a maximum possible score of 26 and a minimum of 0 . Performance of statistical analysis using IBM SPSS to tabulate the results based on mean and standard deviations into low, medium, and high categories of knowledge. The Pearson's Correlation and Step-wise Regression of the knowledge score on retail marketing with socio-personal, economic, and psychological, market-related, and communication variables were done to get deeper insights on factors that show a significant relationship.

\section{RESULTS AND DISCUSSION}

From Table-1 it is shown that the majority (64.00\%) of the vegetable growers occupied the medium knowledge category; 20.00 per cent of respondents had low knowledge, and only 16.00 per cent had high level knowledge of retail marketing. This high knowledge could be attributed to respondents' participation in retail marketing a few years back and interactions with the retail marketing firms. The results are in line with the study executed by Anusuya (2015) on cashew growers.

The respondents with medium knowledge were aware of existing retail entities in their area, advantages of practicing retail marketing, method of sale but lacked clarity on the price fixation, agreement clauses, quality standards, quantity requirements, and additional services provided. Even when most vegetable growers represent a medium knowledge, the high Standard deviation of the sample response shows that the variation at the individual level is more. This finding was affirmed by Prasad et al. (2018)

Table 1 - Distribution of respondents according to their level of knowledge on retail marketing.

\begin{tabular}{|c|c|c|c|c|}
\hline Category & Score & Range & Number & Per cent \\
\hline Low level of knowledge & Below Mean - S.D & $<3.815$ & 30 & 20.00 \\
\hline Medium level of knowledge & Between Mean \pm S.D & $3.815-15.051$ & 96 & 64.00 \\
\hline \multirow[t]{2}{*}{ High level of knowledge } & Above Mean + S.D & $>15.051$ & 24 & 16.00 \\
\hline & & TOTAL & 150 & 100.00 \\
\hline Mean $=9.43$ & & & & $=5.618$ \\
\hline
\end{tabular}

$107|10-12| 2$ 
The vegetable growers with lower knowledge level had difficulties in stating the entities of the retail market and method of sale through retail marketing along with those mentioned above lacunae. The survey results also found that 10.00 per cent of the sample population lack awareness, knowledge and bagged zero scores. Lower education level, trivial information-seeking attitude, and considering agriculture for subsistence could be the factors for vegetable growers' lower knowledge level.

The establishment of new vegetable collection centers by retail agencies, training sessions on the grading of vegetables, transparent pricing mechanisms will contribute to a rise in farmers' level of knowledge on retail markets and participation.

The profile of the vegetable growers was also studied when approached to understand their knowledge of retail marketing. Table 2 gives the results of the test of correlation between these independent variables and knowledge. It could be interpreted that education, area under vegetable production, market orientation, market Intelligence, information seeking behavior, and decision-making ability showed a significant positive relationship at 1 per cent significance level.

It means knowledge of the vegetable growers can be improved with a 99 per cent confidence level by educating them, increasing the area kept for vegetable cultivation, their market orientation, and market intelligence. The enhanced information seeking and decision-making will contribute to knowledge positively.

Education and information-seeking efforts of the individuals open new arenas from which information could be collected, which builds the individual's knowledge. Market orientation, market intelligence, and decision-making aid in exploring and comparing different existing markets and choosing the economically efficient and feasible marketing system.

Table 2 - Values of Pearson Correlation coefficient illustrating their relationship with dependent variable

(Y - Knowledge on retail marketing)

\begin{tabular}{cll}
\hline S.No & \multicolumn{1}{c}{ Variables $\left(\mathbf{X}_{\mathbf{1}}-\mathbf{X}_{\mathbf{1 5}}\right)$} & \multicolumn{1}{c}{$\begin{array}{c}\text { Correlation } \\
\text { Value }(\mathbf{r})\end{array}$} \\
\hline 1. & Age & $-0.195 *$ \\
2. & Education & $0.455 * *$ \\
3 & Occupation & -0.79 \\
4 & Land Holding & $0.207 *$ \\
5 & Area under vegetable production & $0.342 * *$ \\
6 & Experience in vegetable farming & $-0.194 *$ \\
7 & Annual Income & -0.026
\end{tabular}

\begin{tabular}{cll}
8 & Market orientation & $0.427 * *$ \\
9 & Market Intelligence & $0.294 * *$ \\
10 & Information seeking behaviour & $0.276 * *$ \\
11 & Decision-making ability & $0.268 * *$ \\
12 & Economic motivation & $0.174 *$ \\
13 & Credit orientation & 0.148 \\
14 & Infrastructure facilities & -0.159 \\
15 & Market facilities & -0.031 \\
\hline ** - Correlation is significant at 0.01 level (2- tailed) \\
* - Correlation is significant at 0.05 level (2- tailed)
\end{tabular}

Economic motivation and landholding were significantly positive at 5 per cent, on par with findings of Prakash (2008), Whereas age and experience in vegetable farming showed a similar significance but in the opposite direction, i.e., Negative. The possible reason could be that as age and experience increased, the vegetable farmers are habituated and conditioned with the existing marketing system and did not make an effort to gain knowledge about retail marketing.

Step-wise Regression analysis was performed and tabulated to quantify the relationship further and mathematically explain the strength of association.

In a forward regression selection, variables were added one by one into an empty model, whereas in the backward selection, each variable was removed from a full model and the variable is retained on satisfying the threshold value criteria. Once fixed/ removed, the variable does not leave/ enter the model respectively, which stands as a significant drawback.

Step-wise multiple regression is the sum of forward and backward selection regression, overcoming the drawbacks of both. Variables can re-enter as the model proceeds. It has two threshold values for entry and exit (in this study The probability of entering and removing is 0.050 , $0.100)$. The variables that are significant in reducing the sum of squares of error will stay in the model.

The total variability explained by all the 15 independent variables on the dependent variable was 43.80 per cent of the coefficient of determination $\left(R^{2}\right)$, of which, six variables significantly contributed 39.70 per cent, as presented in Table 3, namely education with an unstandardized coefficient of 0.994 , Market orientation (0.953), area under vegetable production (0.482), annual income (-4.285E-6), economic motivation (0.197), decisionmaking ability (0.222). A diagnostic study can be conducted to determine other variables that could affect vegetable growers' knowledge level. 
Table - 3 Step-wise Logistic Regression of independent variables with the knowledge scores of vegetable growers

\begin{tabular}{clccc}
\hline S.No & Independent Variables & $\begin{array}{c}\text { Un-standardized } \\
\text { Regression Coefficient }\end{array}$ & $\begin{array}{c}\text { S.E. of Partial } \\
\text { regression coefficient }\end{array}$ & t- Value \\
\hline 1. & Education & 0.994 & 0.207 & 4.811 \\
2. & Market orientation & 0.953 & 0.279 & 3.422 \\
3 & Area under vegetable production & 0.482 & 0.186 & 2.588 \\
4 & Annual Income & $-4.285 \mathrm{E}-6$ & 0.00 & -3.053 \\
5 & Economic motivation & 0.197 & 0.088 & 2.247 \\
6 & Decision-making ability & 0.222 & 0.104 & 2.144 \\
\hline
\end{tabular}

F- Value $=15.706(p<0.01) \quad E-6=10^{-6} \quad R^{2}=39.7 \%$

The unstandardized coefficients are interpreted as - for every unit increase of the independent variable, i.e., education, market orientation, area under vegetable production, annual income, economic motivation, decision-making ability, there will be 0.994, 0.953, 0.482, - 4.285E-6, 0.197, 0.222 change in the knowledge on retail marketing of the vegetable growers respectively.

\section{CONCLUSION}

Reliance, Big Basket, More supermart, Ninja cart are few retail marketing agencies prevailing in the study area could supplement the existing marketing system. In the absence of a standardized scale to measure the knowledge of vegetable growers on retail marketing, a teacher-made test was constructed.

Increased knowledge of the activities, retail marketing procedures will help in increased participation. However, the study results show that the respondents possess medium to low knowledge only. Lack of approachability to these new marketing methods and the simplicity of the regulated markets caused discontinuance and created ignorance among the vegetable growers to acquire knowledge about the new marketing systems even when the existing system is creating losses. It can be improved by altering the education, market orientation, market intelligence, decision-making ability, Economic motivation, and information-seeking behaviour of the vegetable growers as they indicated the existence of significant relationships.

India's food retail market is expected to reach up to Rs. 62 Lakh crores by 2023. In such a scenario, efforts by retail marketing agencies need to be made for enhancing knowledge by the interactions that help to build trust (Lu, 2008), thereby farmers can understand the apparent advantages, attain increased income, and build back the lost motivation towards agriculture.
Also, a recent report, "Digital in India" from Nielsen and the Internet and Mobile Association of India (IAMAI, 2020), revealed that as of November 2019, Rural India has 10.00 per cent more (227 million) active users of the internet than Urban areas (205 million) confer to the farmers in expanding the information sources. Instead of relying only on personal and local sources now, Information and Communication (ICT's) stay as a handy tool. It also helps the retail agencies approach the farmers to inculcate knowledge on quality standards and production technologies.

\section{REFERENCES}

Akter, M., Fan, L., Rahman, M. M., Geissen, V., and Ritsema, C. J. (2018). Vegetable farmers' behaviour and knowledge related to pesticide use and related health problems: A case study from Bangladesh. J. Cleaner Production, 200, 122-133. doi:https:// doi.org/10.1016/j.jclepro.2018.07.130.

Allahyari, M. S., Damalas, C. A., and Ebadattalab, M. 2017. Farmers' technical knowledge about integrated pest management (IPM) in olive production. Agriculture, 7(12). doi:10.3390/ agriculture7120101.

Anusuya, A. 2015. Knowledge, Adoption and Marketing behavior of Cashew growers in Tamilnadu - A Diagnostic study. Unpub. M.Sc.(Ag). Thesis, Tamilnadu Agriculture University, Coimbatore.

FAO. 2010. Organized retailing of fresh fruits and vegetables: is it really helping producers? Retrieved from: Organized retailing of fresh fruits and vegetables: is it really helping producers? I Contract Farming Resource Centre.

Ecowrap. 2020. Agri-reforms politics: Catering to only cereal-producing states \& shunning fruits and vegetables is lazy farming and parochial thinking. Retrieved from https://sbi.co.in/ documents/13958/3312806/121020Ecowrap_20201012.pdf/.

Foltz, B. (Producer). (2021, 13 May). Multiple regression, step-wise regression. Statistics 101. Retrieved from https://youtu.be/An40g_j1dHA. 
Heijden, T. v. d., and Vink, N. 2013. Good for whom? Supermarkets and small farmers in South Africa - a critical review of current approaches to increasing access to modern markets. Agrekon, 52(1), 68-86. doi:10.1080/03031853.2013.778466.

IAMAI and Nilsen. 2020. Digital in India: 2019 - Round 2 report. Retrieved from:

h t t p s: / / c m s.i a mai.in / Content/ ResearchPapers/2286f4d7-424f-4bde-be886415fe5021d5.pdf.

Jaganathan, D., Bahal, R., Burman, R. R., and Lenin, V. 2016. Knowledge level of farmers on organic farming in Tamilnadu. Indian Res., J. Extension Education, 12(3), 70-73.

Kiran, P. S. 2018. Marketing behaviour of chilli growers in Kolhapur district. Unpub. M.Sc.(Ag.) Thesis, MPKVV, Maharashtra.

Kshash, B. H. 2019. Constraints affecting summer vegetable cultivation. International J. Vegetable Science, 25(2), 154-163. doi:10.1080/193152 60.2018 .1487896 .

Lu, H., Trienekens, J. H., Omta, S. W. F., and Feng, S. 2008. Influence of guanxi, trust, and farmerspecific factors on participation in emerging vegetable markets in china. NJAS: Wageningen $\mathrm{J}$. Life Sci., 56(1-2), 21-38. doi:10.1016/S15735214(08)80015-2
Prakash, M. B. 2008. A study on farmers' Awareness and Preference towards Organized vegetable retailing firms. Unpub. M.Sc.(Ag.) Thesis, TNAU, Coimbatore.

Prasad H D, V., Singh, P. K., and Venkataramulu, M. 2018. Study on farmers' level of knowledge towards vegetable cultivation. J. Res., ANGRAU, 46(2), 75-82.

Paul Mansingh, J and Bayissa, D.D. 2017. Knowledge on Improved Practices of Teff by Smallholder Farmers in Ethiopia. J. Extension Education, 29(4). doi:https:// doi.org/10.26725/JEE.2017.4.29.5937-5944.

Rythu Samagra Samachara Sekara (RSSS data). 20192020. Government of Telangana.

Schreinemachers, P., Simmons, E. B., andWopereis, M. C. S. 2018. Tapping the economic and nutritional power of vegetables. Global Food Security, 16, 36-45. doi:https://doi.org/10.1016/j. gfs.2017.09.005.

Srinivas, M. V., Reddy, B. L., and Reddy, Y. V. 2016. Marketing behaviour of vegetable growers. Agri., Update, 11(4), 434-437. 